\title{
Method and Procedure for Economic Evaluation of Improvement Activities
}

\author{
Hirokazu Kono*, Osamu Ichikizaki \\ Graduate School of Business Administration, Keio University, Yokohama, Japan
}

(Received: February 2, 2015 / Revised: June 5, 2015 / Accepted: June 5, 2015)

\begin{abstract}
The purpose of this paper is to propose an appropriate evaluation scheme for improvement activities, based on a simple model comprising cash inflow by sales as well as variable and fixed cost expenditures. The paper distinguishes capacity surplus and capacity shortage situations, and examines economic benefits gained by yield increase improvement and capacity increase. The paper then proposes a basic rule of thumb for economic evaluation of improvement activities. The logic is simple but useful in practice, being conducive towards improvement activities under current economic conditions with uncertainties.
\end{abstract}

Keywords: Improvement Activities, Economic Evaluation, Capacity, Yield, Demand

* Corresponding Author, E-mail: kono@kbs.keio.ac.jp

\section{INTRODUCTION}

In manufacturing operations, various improvement activities, including those aiming at reduction in machine breakdowns or in changeover and setup time, as well as yield increase, are implemented for the enhancement of productivity, quality, lead time, and flexibility. Especially, under recent economic conditions with increasing uncertainties in demand and cost factors, improvement activities for enhancing fundamental capability of manufacturing firms draws particular attention (Kono, 2003, 2009, 2010).

However, methods for appropriately evaluating financial impact on managerial outcomes are still under discussion both among academia and practitioners. For example, improvement in operating procedure results in the decrease of man-hour input required for daily production. Although it is often claimed that the improvement results in reduced labor cost, this evaluation method does not reflect market conditions. Where demand is booming, decrease in man-hour input requirement may increase supply capacity, resulting in sales increase on a corporate level.

Methods for evaluating outcomes of improvement activities are studied in such areas as engineering economy, industrial engineering, cost accounting, and quality management (Senju et al., 1982, 1986, 1994; Nakamura, $1985,2002)$. But evaluation in monetary terms is strongly affected by the procedure of financial accounting, the major purpose of which is to demonstrate economic outcomes of the past financial year to stakeholders. Since the duration of time under consideration is the past year, simply using theories and procedures employed in financial accounting does not lead to appropriate evaluation of improvement activities.

This paper proposes a method and procedure for evaluating economic impact of various improvement activities. The paper presents a simple and comprehensive model of manufacturing operations, paying attention to the balance between market demand and supply capacity. The validity of the proposed method is examined with a numerical example, based on the concept of financial management and engineering economy. The proposed method may prove to be a useful one which 
manufacturing companies can use in appropriately designing and evaluating various types of improvement activities.

\section{ASSUMED IMPACT OF IMPROVEMENT ACTIVITIES}

In general, profit, denoted by $\pi$, generated by producing and selling a single product, is given by

$$
\pi=p \times S-v \times Q-F,
$$

Where, $p$ : unit sales price

$S$ : sales volume

$Q$ : production volume

$v$ : unit variable cost

$F$ : total fixed cost.

Where yield is not $100 \%, S$ is given by $y \times Q$. Therefore, the profit equation incorporating yield is given by:

$$
\pi=p \times y \times Q-v \times Q-F,
$$

where $y$ represents yield and is given by 1.0-defective ratio $f$.

This statement implies that if the yield is improved from $y_{0}$ to $y_{1}\left(y_{0}<y_{1}\right)$, economic benefit $\Delta \pi$ can be obtained by

$$
\Delta \pi=p \times\left(y_{1}-y_{0}\right) \times Q .
$$

If demand quantity is somehow restricted by market conditions, however, this calculation may not hold water.

On the other hand, if yield is improved by decreasing the defective ratio from $f_{0}$ to $f_{1}$, the economic benefit (increase in profit) may be obtained by $v \times\left(f_{0}-f_{1}\right) \times Q$ according to the common theory. While it may appear to be appropriate in terms of cost saving, impact of production volume increase is neglected in this calculation.

Furthermore, if production volume is increased from $Q_{0}$ to $Q_{1}$, it may be correct to say that economic benefit is $(p-v) \times\left(Q_{1}-Q_{0}\right)$. In this calculation, however, market conditions are neglected.

In practice, values of man-hour rate and machinehour rate are typically used in economic evaluation of productivity increase. If a company reduces setup time from 3 hours to 2 hours, the economic benefit can be calculated by multiplying man-hour rate by 1 hour of reduction. If man-hour rate is 4,000 yen, monthly benefit would be $4,000 \times 8$ (hours/day) $\times 20$ (days) yen. But again, the notion of man-hour rate has nothing to do with any terms found in profit equation of (1). Therefore, man-hour rate and machine-hour rate mislead us in economic evaluation of improvement activities.

The purpose of this paper is to identify a method of appropriate economic evaluation for improvement acti- vities, such as yield improvement or capacity increase. In addition, effect of unit-based profit and total-based profit is compared from the viewpoint of adequate evaluation of capacity increase in production.

\section{MODEL FORMULATION}

This section uses the following notations in addition to notations in Section 2:

$$
\begin{aligned}
& C \text { : production capacity } \\
& D \text { : demand quantity }
\end{aligned}
$$

For these notations, the following conditions are satisfied:

$$
\begin{aligned}
& Q \leq C . \\
& S=y \times Q .
\end{aligned}
$$

As an assumption, we can set up a case of $D<S<$ $Q<C$ as illustrated in Figure 1, under the conditions of (4) and (5). It is clear that the sales volume is beyond the demand, resulting in overproduction against demand. Then, production volume is decreased as indicated by arrows in Figure 1, to the level of $D=S$ that results in $Q<C$, as illustrated in Figure 2. This situation, which satisfies

$$
D=S,
$$

and

$$
Q<C,
$$

is referred to as capacity surplus in this paper.

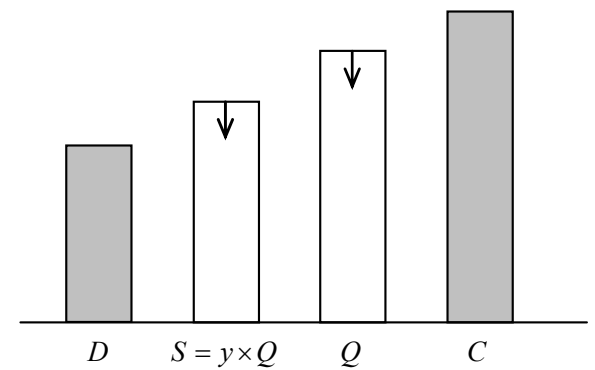

Figure 1. Assumed case of overproduction.

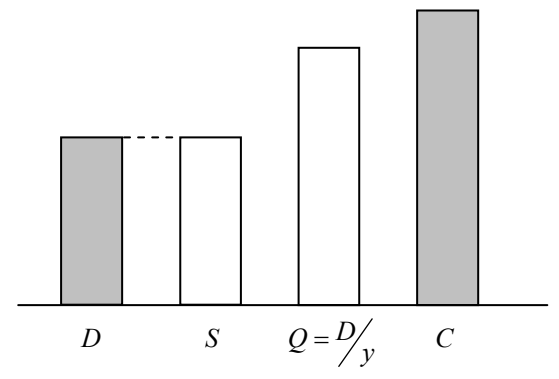

Figure 2. Case of capacity surplus 
Next, let's think of a case in which $S<Q<C$, as well as $D>S$, as illustrated in Figure 3. However large the value $D$ may be, the situation falls into a case of unmet demand, resulting in increase of production volume as illustrated in Figure 3. As a result, $S$ is also increased.

If $S$ reaches the level of $\mathrm{D}(D=S)$ before Q reaching $\mathrm{C}(Q=C)$, then the situation falls into a category of Figure 2, representing the case of capacity surplus. In this case, profit $\pi$ is given by the next statement.

$$
\begin{aligned}
\pi & =p \times S-v \times Q-F \\
& =p \times D-v \times \frac{D}{y}-F .
\end{aligned}
$$

This statement implies that profit is determined as a function of $D$ in the case of capacity surplus.

On the other hand, if $Q$ reaches the level of $C$ $(Q=C)$ before $S$ reaching $D(D=S)$, then the condition of $D>S$ is satisfied as a result, as illustrated in Figure 4. The situation under the condition $Q=C$ as shown in Figure 4 is referred to in this paper as capacity shortage. It should be noted that the capacity shortage situation can be further separated into cases of $D<C$ and $D>C$, implying that capacity shortage is not determined by the balance between $D$ and $C$ as normally pointed out by textbooks of engineering economy, but by the balance between $D$ and $S$. The value of $S$ is affected by the value of production capacity $C$.

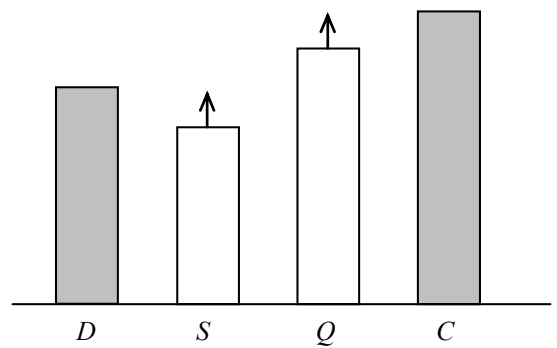

Figure 3. Assumed case of unmet demand.

In the case of capacity shortage, profit $\pi$ is given by the next statement.

$$
\begin{aligned}
\pi & =p \times S-v \times Q-F \\
& =p \times y \times Q-v \times Q-F \\
& =p \times y \times C-v \times C-F .
\end{aligned}
$$

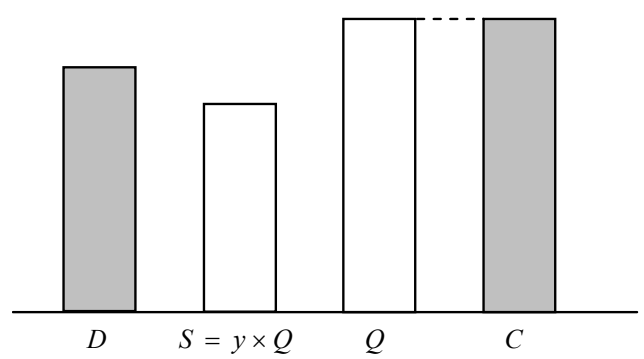

Figure 4. Case of capacity shortage.
This statement implies that profit is determined as a function of $C$ in the case of capacity shortage. Statements (8) and (9) tell us that profit equation differs between cases of capacity surplus and shortage.

\section{EVALUATION OF IMPROVEMENT}

This section examines economic impact of two improvement activities: 1) yield improvement; and 2) capacity increase, for both cases of capacity surplus and capacity shortage. Yield improvement is practicable through quality improvement of raw materials, improvement of inspection devices, or quality improvement activities.

\subsection{Yield Improvement}

The first case is yield improvement, by means of, for example, decrease in production of defects.

In the case of capacity surplus, when yield is improved, it is clear from (5) that the required amount of production is decreased, whereas the total revenue stays the same since demand is already met in full. Therefore, if yield is increased from $y_{0}$ to $y_{1}$, then economic benefit $\Delta \pi$ is obtained from (8) as

$$
\Delta \pi=v \times\left(\frac{D}{y_{0}}-\frac{D}{y_{1}}\right) .
$$

On the other hand, in the case of capacity shortage, yield improvement results in increase of sales, as can be seen from statement (5), whereas production volume, which is the sum of quality products and defective products, remains the same since production is operated to the full capacity. Therefore, from (9), economic outcome $\Delta \pi$ is obtained by the next statement

$$
\Delta \pi=p \times\left(y_{1}-y_{0}\right) \times C .
$$

\subsection{Capacity Increase}

The second case is capacity increase, resulting from such activities as setup time reduction, changeover time reduction, or labor productivity improvement.

In the case of capacity surplus, it is clear from Figure 2 that salable amount is restricted by demand $D$, and therefore, capacity increase does not bring any economic benefit.

On the other hand, in the case of capacity shortage, capacity increase from $C_{0}$ to $C_{1}$ results in increase in salable amount. Thus, until $S$ becomes lower than $D$, economic benefit $\Delta \pi$ is obtained by the next statement.

$$
\begin{aligned}
\Delta \pi & =p \times y \times\left(C_{1}-C_{0}\right)-v \times\left(C_{1}-C_{0}\right) \\
& =(p \times y-v) \times\left(C_{1}-C_{0}\right) .
\end{aligned}
$$


Table 1. Economic benefit of improvement

\begin{tabular}{ccc}
\hline & $\begin{array}{c}\text { Yield Increase } \\
\left(y_{0} \rightarrow y_{1}\right)\end{array}$ & $\begin{array}{c}\text { Capacity Increase } \\
\left(C_{0} \rightarrow C_{1}\right)\end{array}$ \\
\hline $\begin{array}{c}\text { Capacity } \\
\text { Surplus }\end{array}$ & $v \times\left(\frac{D}{y_{0}}-\frac{D}{y_{1}}\right)$ & 0 \\
\hline $\begin{array}{c}\text { Capacity } \\
\text { Shortage }\end{array}$ & $p \times\left(y_{0}-y_{1}\right) \times C$ & $\begin{array}{c}(p \times y-v) \times\left(C_{1}-C_{0}\right) \\
\left(\text { up until } y \times C_{1} \leq D\right)\end{array}$ \\
\hline
\end{tabular}

On the other hand, in the case of capacity shortage, capacity increase from $C_{0}$ to $C_{1}$ results in increase in salable amount. Thus, while $S$ stays lower than $D$, economic benefit $\Delta \pi$ is obtained by the next statement.

$$
\begin{aligned}
\Delta \pi & =p \times y \times\left(C_{1}-C_{0}\right)-v \times\left(C_{1}-C_{0}\right) \\
& =(p \times y-v) \times\left(C_{1}-C_{0}\right) .
\end{aligned}
$$

Furthermore, if capacity is further increased to $C_{2}>$ $C_{1}$, where demand is fully satisfied by $C_{1}$, which means $y \times C_{1}=D$, then the improvement beyond $C_{1}$ does not bring about any economic benefit.

Summarizing the above discussions, economic benefits for each case can be shown in Table 1 .

We can learn from this Table that improvement activities under capacity surplus conditions would bring about either the benefit of reduced variable cost or no benefit at all, while the benefit of those under capacity shortage conditions would be a function of unit sales price p. Therefore, when we plan for improvement activities, whether the situation in question is capacity surplus or capacity shortage needs to be thoroughly investigated with particular attention to the distinction between the two. While a greater effect may be expected from improvement under capacity shortage conditions, it is difficult to promote improvement in such a situation due to shortage in man-power for improvement. In addition, since sales efforts count heavily in determining the balance between capacity and sales, consolidated efforts of sales and supply departments are indispensable. It should also be noted that, in management practice, long-term perspective is required in evaluating efforts of improvement activities. The lack of understanding this simple but practical distinction of capacity surplus and shortage often works as an impediment to an appropriate economic evaluation of improvement activities.

\section{A NUMERICAL EXAMPLE}

The paper assumes the following values:

unit sales price $p=30$ dollars/piece unit variable cost $v=10$ dollars/piece total fixed cost $F=20,000$ dollars production capacity $C=2,000$ pieces/month yield $y=0.9$
Monthly profit under full capacity of production is given by

$$
\begin{aligned}
\pi= & 30(\text { dollars }) \times 0.9 \times 2,000(\text { pieces }) \\
& -10(\text { dollars }) \times 2,000(\text { pieces })-20,000(\text { dollars }) \\
= & 14,000(\text { dollars }) .
\end{aligned}
$$

In the case where the monthly demand $D$ is 1,500 pieces, the situation falls into capacity surplus. The monthly profit in this case is given by

$$
\begin{aligned}
\pi= & 30(\text { dollars }) \times 1,500(\text { pieces }) \\
& -10(\text { dollars }) \times \frac{1,500}{0.9} \text { (pieces)-20,000 (dollars) } \\
= & 8,330(\text { dollars }) .
\end{aligned}
$$

Then, if the yield is improved from 0.9 to 0.95 , benefit is given by

$$
\begin{gathered}
10(\text { dollars }) \times\left(\frac{1,500}{0.9}-\frac{1,500}{0.95}\right)(\text { pieces }) \\
=880(\text { dollars })
\end{gathered}
$$

It can be confirmed that profit with yield 0.95 is given by

$$
\begin{aligned}
\pi= & 30(\text { dollars }) \times 1,500 \text { (pieces }) \\
& -10(\text { dollars }) \times \frac{1,500}{0.95} \text { (pieces) }-20,000(\text { dollars }) \\
= & 9,210(\text { dollars }) .
\end{aligned}
$$

which has increased 880 dollars from the original case.

In the case where the monthly demand $D$ is 2,500 pieces, the situation falls into capacity shortage. Monthly profit is given by (13). If the yield is increased to 0.95 , then the monthly profit increase is given by

$$
\begin{aligned}
\pi & =30(\text { dollars }) \times(0.95-0.9) \times 2,000(\text { pieces }) \\
& =3,000(\text { dollars }) .
\end{aligned}
$$

Meanwhile, if capacity is increased from 2000 to 2200 pieces/month, profit increase is given by

$$
\begin{aligned}
\Delta \pi= & (30(\text { dollars }) \times 0.9-10(\text { dollars })) \\
& \times(2,200-2,000)(\text { pieces }) \\
= & 3,400(\text { dollars }) .
\end{aligned}
$$

If the capacity is increased beyond 2,500/0.9 $=2,778$ (pieces/month), then the situation falls into the case of capacity surplus, bringing no economic benefit even if capacity is further increased.

\section{MEANING OF COST REDUCTION BY CAPACITY INCREASE}

As explained in Table 1, capacity increase brings 
economic benefit in case of capacity shortage until the condition $y \times C \leq D$ is satisfied. Here a simple question may arise: would capacity increase somehow push up the quantity of demand, instead of the demand staying unchanged?

Production capacity is increased normally for reducing manufacturing cost. Since increase in production capacity does not bring any economic benefit in the case of capacity surplus, the case of capacity shortage is considered. Profit per piece of product, denoted by $\pi / C$, is given from (9) by

$$
\frac{\pi}{C}=p \times y-v-\frac{F}{C} .
$$

This implies that the capacity increase from $C_{0}$ to $C_{1}$ can result in increase in profit per piece by $\left(\frac{F}{C_{0}}-\frac{F}{C_{1}}\right)$. It means that, through increasing the capacity while maintaining the profit per piece of product, the unit price may eventually be reduced. This looks reasonable and is often used as a rationale for justifying productivity increase for creating the latitude of price reduction.

In reality, however, there is a larger room for price reduction. The total profit for both cases of capacity $C_{0}$ and $C_{1}$ is given, based on the assumption that the demand quantity can be increased along with the price reduction from $p_{0}$ to $p_{1}$, by

$$
\begin{aligned}
& \pi\left(C_{0}\right)=p_{0} \times y \times C_{0}-v \times C_{0}-F . \\
& \pi\left(C_{1}\right)=p_{1} \times y \times C_{1}-v \times C_{1}-F .
\end{aligned}
$$

For securing profit with capacity $C_{1}$ which is not less than that with capacity $C_{0}$, the statement $\pi\left(C_{1}\right) \geq \pi\left(C_{0}\right)$ must be satisfied. Then from the statement (20) and (21), the value of $p_{1}$ is given by

$$
p_{1} \geq p_{0} \times \frac{C_{0}}{C_{1}}+\frac{v}{y} \times \frac{C_{1}-C_{0}}{C_{1}} .
$$

Taking the case of numerical example in Section 5, based on the assumption that the production capacity is increased from $C_{0}=2,000$ to $C_{I}=2,200$ (pieces/month) for the situation of capacity shortage, the price $p_{I}$ to secure the same monthly profit as with the case of $p_{0}=30$ (dollars/piece), is given from (22) by

$$
\begin{aligned}
p_{1} & =30 \times \frac{2,000}{2,200}+\frac{10}{0.9} \times \frac{2,200-2,000}{2,200} \\
& =28.28 \text { (dollars/piece) } .
\end{aligned}
$$

Total-based profit is calculated as shown in Table 2 . Since the total variable cost increases from 20,000 to 22,000 dollars, the unit sale price required to maintain the total profit of 14,000 dollars is given by

$$
\begin{aligned}
& \text { 56,000 (dollars/month) } / 2,200 \text { (pieces) } \\
& =28.28 \text { (dollars/piece). }
\end{aligned}
$$

It may as well be confirmed that profit under capacity $C_{I}=2,200$ (pieces/month) and $p_{I}=28.28$ (dollar/piece) is given by

$$
\begin{aligned}
\pi\left(C_{1}, p_{1}\right) & =28.28 \times 0.9 \times 2,200-10 \times 2200-20,000 \\
& =14,000(\text { dollars/month }),
\end{aligned}
$$

which is equivalent to $\pi\left(C_{0}, p_{0}\right)$ given in the statement (13).

On the other hand, profit per piece under capacity $C_{0}$ and $C_{l}$, from (20) and (21), is given by

$$
\frac{\pi\left(C_{0}, p_{0}\right)}{C_{0}}=p_{0} \times y-v-\frac{F}{C_{0}},
$$

and

$$
\frac{\pi\left(C_{1}, p_{1}^{\prime}\right)}{C_{1}}=p_{1}^{\prime} \times y-v-\frac{F}{C_{1}},
$$

where $p_{1}^{\prime}$ represents price to assure original profit per piece under the case of $p_{0}$. It follows that $p_{1}^{\prime}$ is given by

$$
p_{1}^{\prime}=p_{0}-\frac{1}{y}\left(\frac{F}{C_{0}}-\frac{F}{C_{1}}\right) \text {. }
$$

For the numerical example,

$$
\begin{aligned}
p_{1}^{\prime} & =30-\frac{1}{0.9} \times\left(\frac{20,000}{2,000}-\frac{20,000}{2,200}\right) \\
& =28.99 \text { (dollars/piece) } .
\end{aligned}
$$

Unit-based calculation is summarized in Table 3. In order to maintain profit per piece of 7 dollars/piece, unit sales-price needs to exceed 28.99 dollars/piece.

This calculation tells us that price per piece can be reduced from $p_{0}=30$ (dollars/piece) to $p_{1}^{\prime}=28.99$ (dollars/piece) while maintaining the same profit per piece as in the original case. It implies that there seems to be a room for price reduction of 1.01 (dollars/piece) $(=30$ 28.99) to realize the actual order of 2,200 (dollars/ month). However, in reality, there is a larger room for price reduction, $1.72(=30-28.28)$ (dollars/piece) as shown in the statement (23). This reveals that per-piece based cost calculation misleads us in evaluating the effect of capacity increase. Instead, we need to pay attention to the total-based profit calculation (refer to Appendix). 
Table 2. Total-based calculation

\begin{tabular}{lcc}
\hline & $\begin{array}{c}\text { before } \\
\left(C_{0}=2,000 \text { pieces) }\right.\end{array}$ & $\begin{array}{c}\text { after } \\
\left(C_{1}=2,200 \text { pieces) }\right.\end{array}$ \\
\hline $\begin{array}{c}\text { sales income } \\
p \times y \times C\end{array}$ & 54,000 (dollars) & $\begin{array}{c}59,400 \text { (dollars) } \\
56,000 \text { (dollars) }\end{array}$ \\
\hline $\begin{array}{c}\text { total variable } \\
\text { cost } v \times C\end{array}$ & 20,000 (dollars) & 22,000 (dollars) \\
\hline fixed cost $F$ & 20,000 (dollars) & 20,000 (dollars) \\
\hline total profit $\pi$ & 14,000 (dollars) & $\begin{array}{c}17,400 \text { (dollars) } \\
14,000 \text { (dollars) }\end{array}$ \\
\hline${ }^{*} p_{1} \times y=56,000$ (dollars) $\div 2,200$ (pieces) $=25.45$ (dollars/piece). \\
$\therefore p_{1}=25.45 \div 0.9=28.28$ (dollars/piece).
\end{tabular}

Table 3. Unit-based calculation

\begin{tabular}{cccc}
\hline & & before $(2,000$ pieces) & after (2,200 pieces) \\
\hline sales price & $p$ & 30 (dollars/piece) & 28.99 (dollars/piece) \\
\hline $\begin{array}{c}\text { nield } \\
\text { net sales } \\
\text { price }\end{array}$ & $y$ & 0.9 (dollars/piece) & 0.9 (dollars/piece) \\
\hline $\begin{array}{c}\text { variable cost } \\
\text { fixed cost } \\
\text { per piece }\end{array}$ & $F / C$ & 10 (dollars/piece) & 10 (dollars/piece) \\
\hline $\begin{array}{c}\text { profit per } \\
\text { piece }\end{array}$ & $\pi / C$ & 7 (dollars/piece) & 7 (dollars/piece) \\
\hline
\end{tabular}

In actual management of productivity, cost, and price issues, many companies consider by separating production (supply) and sales (marketing) functions. In this case, the supply side (production section) increases production capacity for the purpose of cost reduction, while the sales side (sales section) endeavors to receive more orders. If the coordination between the two functions does not work appropriately, the sales function is likely to believe that the room for price reduction is somehow limited (as $p_{1}^{\prime}$ in the numerical example), often resulting in the failure of realizing the order of $C_{1}$. In reality, however, there is a larger room for price reduction than what is believed by the sales function (as $p_{1}$ in the numerical example). Thus, the appropriate management between supply side and demand side is required, based on economic calculation of total cost and total profit.

It is truly important that the supply side, which has control over production capacity, maintains sound communication with the sales section, which controls unit sales price and demand quantity eventually. It should be remembered how critical it is to maintain sound supply chain coordination, which would be hard to achieve if production and sales sections are separated by sectionalism.

\section{CONCLUDING REMARKS}

This paper delved into the problem of evaluation of improvement activities, from the perspective of economic income and expenditure. It examined mainly two case of yield improvement and capacity increase. It also presented the notion of capacity surplus and capacity shortage, which represents the balance between demand quantity and salable amount.

The fundamental principles described in this paper are not complicated, and can be summarized as follows:

1) We need to identify cases of comparison, namely, which cases to be compared.

2) Differences among cases in terms of cash income and cash expenditure need to be clarified.

3) The balance between demand and salable amount needs to be considered. Economic outcome differs between cases of capacity surplus and those of capacity shortage.

4) Capacity surplus/shortage is determined by $D$ (demand) and $S$ (supply), but not by $D$ (demand) and $C$ (capacity).

5) Economic result differs between capacity surplus and shortage situations.

6) The difference should be calculated on the basis of total amount, not on the per-piece basis. Evaluation on the unit profit basis would lead us to misunderstanding; evaluation on the total profit basis is always more appropriate in economic evaluation.

\section{REFERENCES}

Kono, H. (2003), A Method for Evaluating Investment Alternatives on the Total-Cost Unit-Cost Domain, Proceedings for the Autumn Conference of the Japan Industrial Management Association, Osaka, 124-125.

Kono, H. and Mizumachi, T. (2004), Economic Evaluation for Multiple Investment Alternatives under Uncertainty, Proceedings of the 5th Annual Conference of Asia-Pacific Industrial Engineering and Management Systems, Gold Coast, Australia, 8.3.18.3.10.

Kono, H. and Mizumachi, T. (2009), Profit Sensitivity Analysis under Uncertainty for Cases of Production Capacity Surplus and Shortage, Journal of Japan Industrial Management Association, 59(6), 464-476.

Kono, H. (2010), Economic Risk Analysis for Investment Alternatives Considering Yield and Capacity over Multiple Periods, Journal of Japan Industrial Management Association, 60(6E).

Nakamura, Z. (1985), Economic Evaluation on the Variable-Cost Fixed-Cost Domain, Proceedings for the Spring Conference of the Japan Industrial Management Association, Tokyo, 209-210.

Nakamura, Z. (2002), Safety Indices of Profit under Uncertainties, Proceedings for the Autumn Conference 
of the Japan Industrial Management Association, Fukuoka, 54-55.

Senju, S. and Fushimi, T. (1982), Fundamentals of Engineering Economy, Japan Management Association Press, Tokyo.

Senju, S., Fujita S., Fushimi T., Yamaguchi T. (1986), Engineering Economic Analysis, Nihon Kikaku Kyokai, Tokyo.

Senju, S., Nakamura, Z. and Niwa, A. (1994) Exercises of Engineering Economy, Japan Management Association Press, Tokyo.

\section{Appendix}

From the statement (22), price $p_{1}$ to secure the same profit as the original case of $p_{0}$ is given by

$$
p_{1}=p_{0} \times \frac{C_{0}}{C_{1}}+\frac{v}{y} \times \frac{C_{1}-C_{0}}{C_{1}} .
$$

On the other hand, the statement (28) shows that price $p_{1}^{\prime}$ for maintaining the equal profit per piece is given by

$$
p_{1}^{\prime}=p_{0}-\frac{1}{y}\left(\frac{F}{C_{0}}-\frac{F}{C_{1}}\right) \text {. }
$$

Then,

$$
p_{1}^{\prime}-p_{1}=p_{0} \times \frac{C_{1}-C_{0}}{C_{1}}-\frac{v}{y} \times \frac{C_{1}-C_{0}}{C_{1}}-\frac{1}{y} \times\left(\frac{F}{C_{0}}-\frac{F}{C_{1}}\right) .
$$

It follows,

$$
\begin{aligned}
C_{1} & \times y \times\left(p_{1}^{\prime}-p_{1}\right) \\
& =p_{0} \times y \times\left(C_{1}-C_{0}\right)-v \times\left(C_{1}-C_{0}\right)-\left(\frac{F}{C_{0}}-\frac{F}{C_{1}}\right) \times C_{1} \\
& =p_{0} \times y \times\left(C_{1}-C_{0}\right)-v \times\left(C_{1}-C_{0}\right)-\frac{F}{C_{0}} \times\left(C_{1}-C_{0}\right) \\
& =\left(p_{0} \times y-v-\frac{F}{C_{0}}\right) \times\left(C_{1}-C_{0}\right) \\
& =\frac{\pi\left(C_{0}, p_{0}\right)}{C_{0}} \times\left(C_{1}-C_{0}\right) .
\end{aligned}
$$

Therefore,

$$
p_{1}^{\prime}-p_{1}=\frac{\pi\left(C_{0}, p_{0}\right)}{C_{0}} \times \frac{1}{y} \times\left(\frac{C_{1}-C_{0}}{C_{1}}\right) .
$$

Therefore $p_{1}^{\prime}-p>0$ is satisfied, if the profit for the original case $\pi\left(C_{0}, p_{0}\right)$ is positive. It means that $p_{1}<p_{1}^{\prime}$, thus the room for price reduction on the totalprofit basis $\left(p_{1}-p_{0}\right)$ is larger than that in the case based on the per-piece basis $\left(p_{1}^{\prime}-p_{0}\right)$. 